\title{
Influence of alternating temperature preculture on cryopreservation results for potato shoot tips
}

\author{
Anja Kaczmarczyk • Natalia Shvachko • \\ Yulia Lupysheva · Mohammad-Reza Hajirezaei • \\ E. R. Joachim Keller
}

Received: 29 February 2008 / Revised: 15 May 2008/ Accepted: 12 June 2008 / Published online: 28 June 2008

(C) The Author(s) 2008

\begin{abstract}
Cryopreservation is the most suitable long-term storage method for genetic resources of vegetatively maintained crops like potato. In the Leibniz Institute of Plant Genetics and Crop Plant Research (IPK) the DMSO droplet method is applied, and so far more than 1000 accessions are cryopreserved with an average regeneration rate of 58\%. New experiments with four potato accessions using alternating temperatures $\left(22 / 8^{\circ} \mathrm{C}\right.$ day/night temperature, $8 \mathrm{~h}$ photoperiod, $7 \mathrm{~d}$ ) prior to cryopreservation showed improved regeneration. The influence of this preculture on the shoot tips was studied for two wild, frost resistant species Solanum acaule and S. demissum and for two cultivated, frost sensitive potatoes $S$. tuberosum 'Désirée' and 'King Edward'. Comparison of liquid and solid media after cryopreservation showed improved regeneration on solid media with higher regeneration percentages, less callus formation and better plantlet structure. In comparative analyses biochemical factors like soluble sugars, starch, and amino acid concentrations were measured. Shoot tips after constant and after alternating temperature preculture were analyzed. Total concentrations of soluble sugars (glucose, fructose, and sucrose) were higher for all accessions after the alternating temperature preculture, which could be the reason for improved cryopreservation results.
\end{abstract}

Communicated by M. Petersen.

A. Kaczmarczyk · M.-R. Hajirezaei · E. R. J. Keller ( $\square)$ Leibniz Institute of Plant Genetics and Crop Plant Research (IPK), Corrensstrasse 3, 06466 Gatersleben, Germany e-mail: keller@ipk-gatersleben.de

N. Shvachko - Y. Lupysheva

All-Russian Institute of Plant Industry (VIR),

Bolshaja Morskaja 42/44, Saint-Petersburg, Russia
Keywords Solanum tuberosum - Solanum acaule . Solanum demissum . DMSO droplet method .

Carbohydrates · Amino acids

\begin{abstract}
Abbreviations
CT Constant temperature preculture $\left(22^{\circ} \mathrm{C}\right.$ constant temperature 7 days)

AT Alternating temperature preculture $\left(22 / 8^{\circ} \mathrm{C}\right.$ day/night temperature 7 days)
\end{abstract}

\section{Introduction}

Cryopreservation as long-term storage method for genetic resources of potato achieved, next to the in vitro storage, a greater scientific and economic importance in recent years. Cryopreservation has the advantage to be a safe, fast and less labour consuming method to store germplasm compared to in vitro and field maintenance. For potato many studies about different methods of cryopreservation already exist (Bajaj 1977; Benson et al. 1989; Fabre and Dereuddre 1990; Golmirzaie and Panta 2000; Halmagyi et al. 2005; Hirai and Sakai 1999). At IPK, cryopreservation of potato is carried out using the DMSO droplet method (Schäfer-Menuhr et al. 1994) which was mainly empirically optimised.

Cold precultures of donor plants before cryopreservation are known to improve results for woody (Chang and Reed 2000; Niino and Sakai 1992) and herbal species (Keller 2005; Reed et al. 2003; Seibert and Wetherbee 1977), which are able to cold-acclimate to low temperatures. Also in other species like yam, which are not usually able to acclimate to cold temperatures, cryopreservation results could be improved after exposure to low temperature (Leunufna and Keller 2005). For potato low temperature 
precultures were applied before cryopreservation using encapsulation-vitrification and droplet-vitrification methods (Halmagyi et al. 2005; Hirai and Sakai 2000; Kryszczuk et al. 2006), but with weaker results when compared with the original protocols. However, Kryszczuk et al. (2006) used alternating temperature preculture of 7 days with $21 / 8^{\circ} \mathrm{C}$ (day/night temperature) and could improve results in four potato accessions tested by applying the DMSO droplet method. Preliminary experiments at IPK showed that alternating temperature preculture (AT, $22 / 8^{\circ} \mathrm{C}$ day/night temperature, 7 days) led to improvement of the regeneration after cryopreservation using the DMSO droplet method. Cultivated potatoes (S. tuberosum) belong to the group of frost sensitive potatoes and are unable to acclimate to low temperatures ( $\mathrm{Li}$ 1977), whereas other species like $S$. acaule and $S$. demissum belong to the frost resistant potatoes and are able to cold-acclimate ( $\mathrm{Li}$ and Fennel 1985; Mastenbroek 1956).

The aim of this study was to establish a suitable method for the improvement of cryopreservation results after AT for cultivated and wild potato accessions. A comparison of liquid and solid regeneration media has been done to test the influence of medium consistency on shoot regeneration. Cultivated and wild species were compared to see, if the ability to cold-acclimate can be correlated to cryopreservation results. Parallel to cryopreservation experiments biochemical compounds like soluble sugars, starch and amino acids were analyzed to find out whether biochemical markers can be identified which might be used to improve cryopreservation method.

\section{Materials and methods}

\section{Plant material}

Solanum tuberosum 'Désirée', 'King Edward', S. acaule and $S$. demissum were obtained from Groß Lüsewitz Cultivated Potato Collection, Germany, a branch station of IPK. Cultivated accessions are maintained there as tubers in the field and/or as in vitro plants. In vitro cultures are preserved in cycles consisting of cold storage of microtubers at $4^{\circ} \mathrm{C}$ and a warm sprouting and multiplication phase at $20^{\circ} \mathrm{C}$ (Thieme 1992). Wild potatoes are maintained as seeds and tubers. Initiation of in vitro cultures of 'Désirée' was in 1996 and of 'King Edward' in 1994. S. acaule was received as tubers and $S$. demissum as seeds. Both were put into in vitro culture in 2005 .

\section{Explant sterilization}

Tubers of $S$. acaule were put in the dark for sprouting for 8 weeks. Dark-grown sprouts were cut in nodal segments and rinsed in $70 \%$ ethanol. Afterwards segments were placed into an Erlenmeyer flask and shaken in 25\% sodium hypochlorite solution for $10 \mathrm{~min}$. Then segments were washed three times with sterile water under sterile conditions. Nodal segments were dried on filter paper, and bleached ends were cut off. At last segments were put onto MS medium (Murashige and Skoog 1962) with 3\% sucrose for the establishment of in vitro culture.

Solanum demissum seeds were also washed in $25 \%$ sodium hypochlorite solution for $10 \mathrm{~min}$ and rinsed with sterile water afterwards. Seeds were placed on MS medium with $3 \%$ sucrose for germination.

From each wild species one clone was chosen, multiplied and used for experiments.

Explant cultivation

In vitro plants used as source for shoot tips were multiplied by nodal cuttings and grown for 3 weeks on solidified medium MS supplemented with $2 \%$ sucrose and $10 \mathrm{~g} / \mathrm{l}$ agar. They were maintained under a $16 \mathrm{~h}$ photoperiod at $22^{\circ} \mathrm{C}$. Afterwards two precultures were applied, each for 7 days. The first comprised $22^{\circ} \mathrm{C}$ constant temperatures with $16 \mathrm{~h}$ photoperiod (CT). The second consisted of alternating temperatures of $22 / 8^{\circ} \mathrm{C}$ day/night temperature with $8 \mathrm{~h}$ photoperiod (AT). Light intensity for maintenance of cultures was about $70 \mu \mathrm{mol} \mathrm{s}{ }^{-1} \mathrm{~m}^{-2}$.

\section{Cryopreservation procedure}

Apical shoot tips (approximately $3 \mathrm{~mm}$ long and $0.5 \mathrm{~mm}$ thick) were isolated and placed in liquid MS solution with $3 \%$ sucrose, $0.5 \mathrm{mg} / \mathrm{l}$ zeatin riboside, $0.5 \mathrm{mg} / \mathrm{l}$ indole acetic acid, and $0.2 \mathrm{mg} / \mathrm{l}$ gibberellic acid (MSH) overnight. On the second day the shoot tips were placed in cryoprotectant solution (MSH with 10\% DMSO) for $2 \mathrm{~h}$. They were then transferred into $2.5 \mu \mathrm{l}$ drops of cryoprotectant solution placed on a small piece of heat-sterilized aluminium foil and quickly cooled in liquid nitrogen (LN). The foils were transferred in cryovials and stored in LN for $1 \mathrm{~h}$ (SchäferMenuhr et al. 1994).

\section{Rewarming}

Shoot tips were rewarmed by placing the aluminium foils in liquid MS medium at room temperature for 1-5 min. Afterwards liquid and solid regeneration media were compared. For regeneration in liquid medium, shoot tips were placed in drops of warmed agarose in small plastic Petri dishes. After solidification of the drops, liquid MSH solution was added (Schäfer-Menuhr et al. 1994). In comparison to the former mentioned method, shoot tips were placed directly after rewarming on solid medium 
(MSH with $10 \mathrm{~g} / \mathrm{l}$ agar). Subsequently Petri dishes of both variants were cultivated for regeneration in a climate chamber with $25 / 20^{\circ} \mathrm{C}$ (day/night temperature) and $16 \mathrm{~h}$ photoperiod (light intensity about $50 \mu \mathrm{mol} \mathrm{s}{ }^{-1} \mathrm{~m}^{-2}$ ).

Determination of soluble sugars and starch

Soluble sugars and starch were determined in shoot tips homogenized under liquid nitrogen, extracted with $80 \%$ ethanol and measured in an enzyme-coupled assay according to Hajirezaei et al. (2006).

Determination of amino acids

Amino acids in shoot tips were measured using a reversedphase HPLC system as described by Rolletschek et al. (2002). The same material was used for the determination of soluble sugars and starch analyses according to Chen et al. (2005).

\section{Statistics}

Statistical analyses of cryopreservation results were done using the $\chi^{2}$ test. Results are shown as means of three repetitions with approximately 30 shoot tips per experiment. For statistical comparison of sugar, starch and amino acid results t-test was used. When normality test failed Mann-Whitney Rank sum test was used. Results are shown as means of three experiments with seven to ten repetitions each, one repetition consisting of 20-50 shoot tips. Calculations were done using the statistical software programm SigmaStat 3.1, Systat Software, Inc.

\section{Results}

Cryopreservation results after alternating temperature preculture

AT of $S$. tuberosum 'Désirée', 'King Edward', $S$. acaule and $S$. demissum in vitro plants for 7 days prior to cryopreservation resulted in an increase of the regeneration capacity of the shoot tips (Table 1). Similar results were found for six other accessions (data not shown). The average percentage of survived shoot tips was $88.7 \%$ after $\mathrm{CT}$ and $91.6 \%$ after AT (including all green explants like shoots, leaves, and callus). However, only green shoots were counted for determination of the regeneration percentages. These were single or multiple shoots regrown from original shoot tip. Mean shoot regeneration was $34.6 \%$ after $\mathrm{CT}$ in experiments using agarose drops and liquid regeneration medium, which increased to $45.2 \%$ in variants subjected to AT (Table 1).

Comparison between liquid and solid regeneration media

Comparisons of two media were conducted, because preliminary experiments revealed better regeneration on solid media. This was proved in the present study.

Improvement of the cryopreservation results was achieved after preculture at AT for both media used. Only S. tuberosum 'King Edward' did not show improvement in regeneration results after AT in agarose drops with liquid medium. After AT the wild species $S$. acaule and $S$. demissum had significantly higher regeneration (Table 1) in agarose drops with

Table 1 Shoot regeneration in control $(-\mathrm{LN})$ and cryopreserved explants $(+\mathrm{LN})$ after constant temperature preculture $\left(\mathrm{CT}, 22^{\circ} \mathrm{C}\right.$ constant temperature, 7 days) and alternating temperature preculture (AT, $22 / 8^{\circ} \mathrm{C}$ day/night temperature, 7 days)

\begin{tabular}{|c|c|c|c|c|c|c|c|c|c|}
\hline \multirow{3}{*}{$\begin{array}{l}\text { Preculture } \\
\text { Regeneration media } \\
\text { Accession }\end{array}$} & \multirow[b]{3}{*}{$\mathrm{LN}$} & \multicolumn{4}{|l|}{ CT } & \multicolumn{4}{|l|}{ AT } \\
\hline & & \multicolumn{2}{|c|}{ Liquid } & \multicolumn{2}{|l|}{ Solid } & \multicolumn{2}{|c|}{ Liquid } & \multicolumn{2}{|l|}{ Solid } \\
\hline & & $\mathrm{S}$ & $\mathrm{R}$ & $\mathrm{S}$ & $\mathrm{R}$ & $\mathrm{S}$ & $\mathrm{R}$ & $\mathrm{S}$ & $\mathrm{R}$ \\
\hline \multirow[t]{2}{*}{ S. tuberosum 'Désirée' } & - & 100.0 & 97.8 & 100.0 & 100.0 & 100.0 & 98.9 & 100.0 & 100.0 \\
\hline & + & 70.0 & 12.2 & 48.1 & 19.0 & 88.9 & 23.3 & 73.5 & $44.6 * *$ \\
\hline \multirow[t]{2}{*}{ S. tuberosum 'King Edward' } & - & 100.0 & 93.3 & 95.8 & 95.8 & 98.9 & 88.0 & 100.0 & 98.6 \\
\hline & + & 90.8 & 21.8 & 77.8 & 44.4 & 81.1 & 16.7 & 86.3 & $75.0 *$ \\
\hline \multirow[t]{2}{*}{ S. acaule } & - & 100.0 & 97.7 & 100.0 & 95.6 & 100.0 & 98.8 & 100.0 & 100.0 \\
\hline & + & 94.3 & 36.8 & 80.2 & 25.3 & 97.7 & $55.8 *$ & 83.5 & 33.0 \\
\hline \multirow[t]{2}{*}{ S. demissum } & - & 100.0 & 91.2 & 100.0 & 97.7 & 98.9 & 97.7 & 100.0 & 98.8 \\
\hline & + & 100.0 & 67.4 & 92.5 & 62.4 & 98.9 & $85.6 * *$ & 94.7 & 82.1** \\
\hline Mean & - & 100.0 & 95.0 & 99.1 & 97.2 & 99.7 & 95.7 & 100.0 & 99.4 \\
\hline Mean & + & 88.7 & 34.6 & 75.6 & 38.4 & 91.6 & 45.2 & 84.8 & 58.7 \\
\hline
\end{tabular}

Comparison of survival ( $\mathrm{S}$, shoots, leaves and callus, in percentage) and shoot regeneration (R, only shoots, in percentage) using agarose drops in liquid and solid regeneration media. Results are means of three experiments with approximately 30 shoot tips each tested. Mean is calculated from total shoot tip number. Significances are calculated for the comparison within the same media and between precultures (no comparison between $\mathrm{S}$ and $\mathrm{R})$. Values in bold with asterisk mark significant changes after AT $(* P<0.05 ; * * P<0.01)$ 
Table 2 Concentrations of total, single soluble sugars and starch in $\mu \mathrm{mol} / \mathrm{g} \mathrm{FW} \pm$ standard error in shoot tips after constant temperature preculture $\left(\mathrm{CT}, 22^{\circ} \mathrm{C}\right.$ constant temperature, 7 days) and alternating temperature preculture (AT, 22/8 ${ }^{\circ} \mathrm{C}$ day/night temperature, 7 days)

\begin{tabular}{|c|c|c|c|c|c|c|c|c|}
\hline & \multicolumn{4}{|l|}{$\mathrm{CT}$} & \multicolumn{4}{|l|}{ AT } \\
\hline & $\begin{array}{l}\text { S. tuberosum } \\
\text { 'Désirée' }\end{array}$ & $\begin{array}{l}\text { S. tuberosum } \\
\text { 'King Edward' }\end{array}$ & S. acaule & S. demissum & $\begin{array}{l}\text { S. tuberosum } \\
\text { 'Désirée' }\end{array}$ & $\begin{array}{l}\text { S. tuberosum } \\
\text { 'King Edward' }\end{array}$ & S. acaule & S. demissum \\
\hline Sugars total & $9.22 \pm 1.11$ & $9.48 \pm 0.96$ & $38.26 \pm 4.14$ & $16.34 \pm 2.21$ & $15.94 \pm 1.29 *$ & $9.90 \pm 1.05$ & $41.67 \pm 3.42$ & $29.51 \pm 2.95^{*}$ \\
\hline Glucose & $4.01 \pm 0.45$ & $5.66 \pm 0.60$ & $28.78 \pm 2.96$ & $12.51 \pm 1.54$ & $10.86 \pm 0.83 *$ & $6.91 \pm 0.78$ & $31.54 \pm 2.50$ & $24.83 \pm 2.36^{*}$ \\
\hline Fructose & $4.18 \pm 0.55$ & $2.71 \pm 0.25$ & $7.28 \pm 0.88$ & $2.03 \pm 0.36$ & $4.28 \pm 0.36$ & $1.72 \pm 0.18$ & $8.12 \pm 0.72$ & $2.36 \pm 0.23$ \\
\hline Sucrose & $1.03 \pm 0.11$ & $1.10 \pm 0.11$ & $2.20 \pm 0.30$ & $1.80 \pm 0.30$ & $0.80 \pm 0.09$ & $1.27 \pm 0.09$ & $2.01 \pm 0.19$ & $2.32 \pm 0.36$ \\
\hline Starch & $1.83 \pm 0.15$ & $0.22 \pm 0.02$ & $2.42 \pm 0.24$ & $1.54 \pm 0.20$ & $0.79 \pm 0.07 *$ & $0.45 \pm 0.12$ & $1.84 \pm 0.25$ & $0.85 \pm \mathbf{0 . 0 9} *$ \\
\hline
\end{tabular}

Results are shown as means of three experiments with 7-10 repetitions each, one repetition consisting of 20-50 shoot tips. Values in bold with asterisk mark significant changes after AT $(P<0.05)$

liquid medium. The improvement in regeneration percentages was stronger on solid medium, on which $S$. tuberosum 'Désirée', 'King Edward', and S. demissum showed significantly higher regrowth after AT (Table 1).

Average regeneration of plants was always higher using solid medium for the four accessions tested. After CT shoot regeneration was $34.6 \%$ on liquid medium and $38.4 \%$ on solid medium. Whereas after AT regeneration was $45.2 \%$ in liquid medium and $58.7 \%$ on solid medium (Table 1). Furthermore, the increment in regeneration after AT was better on solid regeneration medium, where $S$. tuberosum 'Désirée' improved regeneration by $25.6 \%$, S. tuberosum 'King Edward' by $30.6 \%$ and S. demissum by $19.7 \%$. Only $S$. acaule showed less increment in regeneration on solid medium when compared with liquid medium. The improvement of results was especially prominent in cultivated potatoes, which had low or average regeneration using the original protocol (Schäfer-Menuhr et al. 1994).

Determination of soluble and insoluble sugars

Total soluble sugar concentrations increased for all accessions after exposure to AT (Table 2). In S. tuberosum 'Désirée' and $S$. demissum increments were statistically significant. The increment was mainly due to glucose, because only this sugar increased significantly. Fructose and sucrose showed only minor changes after AT (Table 2). Total concentrations of soluble sugars were further higher for the wild species $S$. acaule and $S$. demissum compared to the cultivated accessions.

Starch concentrations decreased significantly after AT in S. tuberosum 'Désirée' and S. demissum but not significantly in S. acaule. In S. tuberosum 'King Edward' no significant change was found in starch concentration after AT (Table 2).

Determination of amino acids

Concentrations of seventeen essential amino acids were determined. Out of these, asparagine showed significant increase after AT in S. tuberosum 'Désirée' and S. acaule whereas asparagine did not change significantly in $S$. $t u$ berosum 'King Edward'. A slight decrease in asparagine concentration was detected in S. demissum. In all accessions asparagine was the predominant amino acid with the highest concentration (Table 3). In contrast to asparagine most other measured amino acids decreased after AT, such as glutamine, glycine and proline (Table 3). Other amino acids, which were measured, had very low concentrations and did not change significantly (data not shown).

\section{Discussion}

Influence of temperature preculture and solid regeneration medium on cryopreservation results

Improvement was found in this study applying AT in donor plants and solid regeneration medium in comparison to the original DMSO droplet method, were donor plants are grown under constant temperatures at $22^{\circ} \mathrm{C}$ and agarose drops with liquid regeneration medium is used (SchäferMenuhr et al. 1994). Similar results concerning preculture were found by Kryszczuk et al. (2006), who could demonstrate that cold preculture of 7 days at $21 / 8^{\circ} \mathrm{C}$ (day/night temperature) increased regeneration rates of four cultivated potato accessions using the original protocol described by Schäfer-Menuhr et al. (1994). The AT always increased the regeneration percentages, independent of the regeneration medium used. Only S. tuberosum 'King Edward' showed decrease in regeneration in liquid medium. Out of different tested preculture temperatures, the oscillation of 22 and $8^{\circ} \mathrm{C}$ between day and night seems to be very important to improve cryopreservation results. In previous studies, other authors (Halmagyi et al. 2005; Hirai and Sakai 1999) used preculture temperatures of constantly $4^{\circ} \mathrm{C}$. However, they failed to show any improvement of cryopreservation results in comparison to control conditions. Based on the 
Table 3 Amino acid concentrations in $\mu \mathrm{mol} / \mathrm{g} \mathrm{FW} \pm$ standard error in shoot tips after constant temperature preculture $\left(\mathrm{CT}, 22^{\circ} \mathrm{C}\right.$ constant temperature, 7 days) and alternating temperature preculture (AT, $22 / 8^{\circ} \mathrm{C}$ day/night temperature, 7 days)

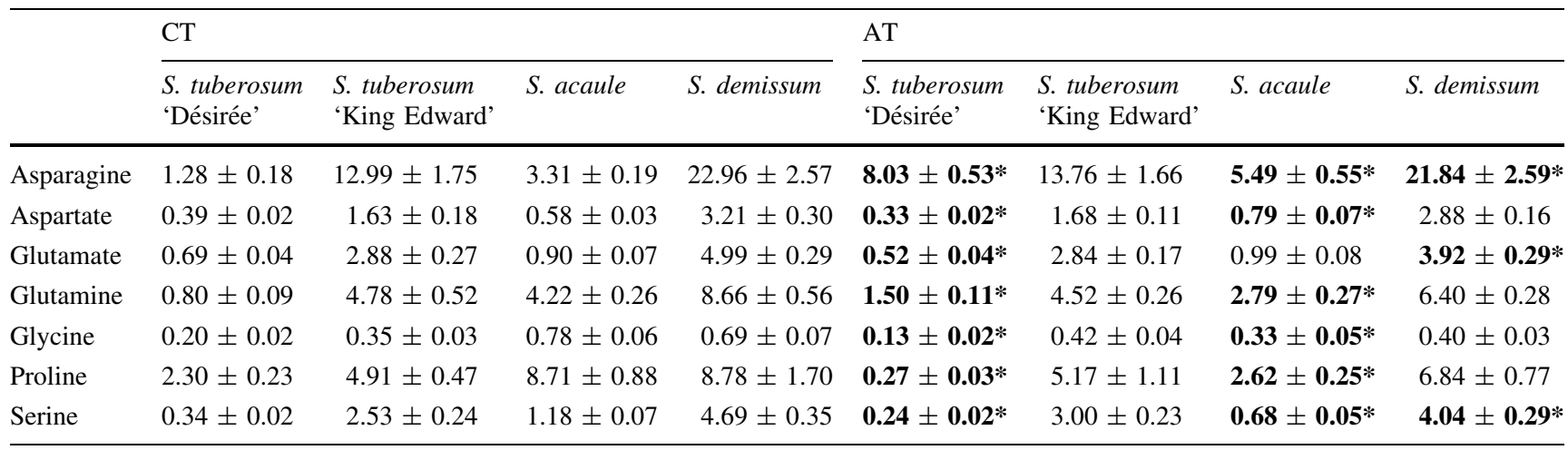

Results are shown as means of three experiments with 7-10 repetitions each, one repetition consisting of 20-50 shoot tips. Values in bold with asterisk mark significant changes after AT $(P<0.02)$

presented results it is suggested that preculture temperatures lower than $8^{\circ} \mathrm{C}$ are not favourable for in vitro plants of potato. In agreement with the shown results, Zhao et al. (2005) could demonstrate that pretreatment of potato plants at $10^{\circ} \mathrm{C}$ resulted in improvement of cryopreservation results. In the experiment using agarose drops with liquid regeneration medium wild species showed better cryopreservation results in comparison to cultivated potatoes. On liquid medium, regeneration percentages of wild species were independent of preculture. Because of those results, a putative connection between frost tolerance of the species and regeneration after cryopreservation was speculated. This was disproved in the next cryopreservation experiment using solid regeneration medium. In this case, both cultivated potatoes showed better regeneration than $S$. acaule after AT. From these results it can be concluded, that the so far obtained cryopreservation results are not directly related to cold acclimation and cold tolerances.

Marga et al. (1997) showed improvement in growth of in vitro apple cultures in medium solidified with high concentrations of agar in comparison to medium with lower agar concentration. Also in this study, comparison of liquid and solid media after rewarming showed that the solid medium was more suitable for regeneration. In the latter case, the regeneration percentages after cryopreservation were higher in S. tuberosum 'Désirée' and 'King Edward'. On solid medium, less callus formation was found and the regenerated plants showed better structure of shoots, leaves and roots. The drier environment and contact with the medium on only one side of the explants could further prevent callus formation and enhance better shoot formation. Furthermore, the method using solid media was faster and easier in handling.

Based on the shown results, it is concluded that the used system increases regeneration after cryopreservation for all accessions, but with highest improvement for such accessions with lower regeneration percentages. Solid regeneration medium showed better results concerning average regeneration percentage, plantlet formation and handling of method. Because of all these positive findings, the DMSO droplet protocol so far used in IPK is recently in change towards application of AT and solid medium for regeneration.

Biochemical changes after AT in connection with cryopreservation results

To induce cold acclimation in potato plants usually temperatures between 2 and $4{ }^{\circ} \mathrm{C}$ are used for experiments ( $\mathrm{Li}$ et al. 1979; Stone et al. 1993; van Swaaij et al. 1985). Li et al. (1979) defined the upper limit of acclimating temperature as between 12 and $13^{\circ} \mathrm{C}$ for $S$. commersonii. In this study, the chosen AT with an oscillation between 22 and $8^{\circ} \mathrm{C}$ lies below this limit. Therefore, it was assumed that cold acclimation takes place during preculture in wild species. From other cryopreservation studies it is known that cold acclimation improves regeneration (Chang and Reed 2000; Niino and Sakai 1992). In this study, it was assumed that, if cold acclimation could be proven through biochemical characteristics, improved results after AT could be related to this aspect.

Cultivated potatoes are known not to be able to coldacclimate ( $\mathrm{Li}$ et al. 1979). But cold precultures applied in tropical and subtropical species, which are also not able to cold-acclimate, have shown improved cryopreservation results (Leunufna and Keller 2005; Chang et al. 2000). Therefore, biochemical compounds were analyzed, which could explain better cryopreservation results after AT.

The process of cold acclimation is a multiple trait with complex physiological and biochemical changes (Hannah 
et al. 2005). A typical characteristic in cold acclimated plants is the increased concentration of soluble sugars (Levitt 1972). This could be found for all analyzed potatoes, although differences were sometimes not significant. After AT, increase in soluble sugar content was highest in S. demissum with $42 \%$ and lowest in S. tuberosum 'King Edward' with $4 \%$ in comparison to CT. Double or higher increase, as reported by $\mathrm{Li}$ et al. (1979) in S. acaule and $S$. tuberosum after hardening at $2{ }^{\circ} \mathrm{C}$ for 15 days, could not be found.

Besides sugar accumulation also starch increases at low temperatures ( $\mathrm{Li}$ and Fennel 1985). This could not be confirmed in the present study. Starch decreased in three accessions (Table 2). Only S. tuberosum 'King Edward' showed no decrease in starch concentration after AT. Because of relatively low increase in sugars and decrease in starch concentration, it was concluded, that the preculture used in this study is not cold enough to induce cold acclimation in potato plants. The observed single changes can, nevertheless, be interpreted as part of the rather complex process of cold acclimation. They are, however, not sufficient to represent the whole acclimation process. The higher soluble sugar concentration could be the reason for improvement of regeneration after cryopreservation. Soluble sugars have been shown to act as cryoprotectants in stabilizing membranes during cooling (Anchordoguy et al. 1987; Hincha 1990) and lowering the cell water content osmotically (Hitmi et al. 1999) to prevent lethal intracellular ice formation. No direct correlation can be found in comparison of absolute concentrations of soluble sugars and cryopreservation results. It can be concluded that cryopreservation success is not related to the absolute sugar concentrations, but to the internal increase in sugars. This conclusion is based on the results of $S$. tuberosum 'Désirée', S. acaule and $S$. demissum in this study. For starch concentration, it seems that the change from high to low concentration is correlated to increased shoot regeneration after cryopreservation. This was found in 'Désirée', $S$. acaule and S. demissum. 'King Edward' did not show this correlation, because this accession did not significantly respond to the changes in conditions. After AT, shoot regeneration was, however, significantly increased also in 'King Edward'.

Concentrations of essential amino acids were measured, in order to find out whether there was a positive correlation to the cryopreservation results. Highest concentrations were found in asparagine, glutamine, glycine and proline. After AT, asparagine increased in three analyzed accessions, and not in S. demissum, which showed minor decrease of this amino acid. Increase of asparagine concentration at low temperatures was already reported by Stewart and Larher (1980), who showed that asparagine positively correlated with freezing tolerance in apple. In the present study, glutamine concentration decreased in three analyzed accessions, but not in S. tuberosum 'Désirée'. Glutamine as well as asparagine belong to the class of nitrogen-containing amino acids, which are transported in plants from source to sink tissues (Lohaus et al. 1998; Urquhart and Joy 1982). It is not clear, why the average glutamine concentration was lower under alternating temperatures in the present study. One possible explanation might be that glutamine was converted to other amino acids, nucleic acids and other nitrogen-containing compounds immediately after production in roots. Most interesting was the change in concentration of proline. For three of the four tested accessions, decrease in proline concentration was measured in the shoot tips after AT. Usually proline is accumulated at low temperatures (Stewart and Larher 1980). This amino acid is known to act as osmoregulator, protective agent for cytoplasmic enzymes and membranes. It is a compound, which accumulates under stress (van Swaaij et al. 1985). It can be assumed that the applied AT is similar to the natural environment of potato species being more favorable than constant warm temperatures usually applied to in vitro cultures. One could speculate that constantly warm temperatures may induce stress rather than alternating temperatures. In general it is known, that soluble nitrogen content increases in plants grown at lower temperatures (Levitt 1972). This could be confirmed for asparagine in the current study. Other amino acids mainly decreased after AT. Possible reasons for the decrease in amino acid concentration could be that AT involved conditions, which did change the amino acid metabolism only partly. Therefore, the typical effects of low temperature application were not detectable. Furthermore, the sugar, starch and amino acid determinations were performed with in vitro plants and shoot tips as source in the present study, whereas in contrast to the findings here, other experiments were carried out using either field or greenhouse plants (Levitt 1972; Li and Fennel 1985; Stewart and Larher 1980). To conclude, biochemical analyses revealed that no cold acclimation took place after AT. Therefore, cryopreservation results cannot be directly related to cold acclimation capacity and cold tolerance under the given environmental conditions in this study. However, improvement of cryopreservation results can be related to increase in soluble sugar concentration. Soluble sugars are known to have important function in osmoprotection, cryoprotection, and metabolization of other protective substances during cryopreservation (Hincha 1990; Hitmi et al. 1999; Towill 1991). In addition, they have hormone-like functions as primary messengers in signal transduction (Rolland et al. 2002). For further improvement of the method, the influence of internal and external sugar concentrations during preculture and cryoprotction should be studied in more detail. Conditions involving lower temperatures in the cold phase, like $22 / 2$ or 
$15 / 2^{\circ} \mathrm{C}$ day/night temperature, should be tested in order to induce increase of the soluble sugar concentrations, which possibly could further improve cryopreservation results.

Acknowledgments The authors wish to thank Marion Grübe and Wally Wendt for their dedicated and skilful work.

Open Access This article is distributed under the terms of the Creative Commons Attribution Noncommercial License which permits any noncommercial use, distribution, and reproduction in any medium, provided the original author(s) and source are credited.

\section{References}

Anchordoguy TJ, Rudolph AS, Carpenter JF, Crowe JH (1987) Modes of interaction of cryoprotectants with membrane phospholipids during freezing. Cryobiology 24:324-331

Bajaj YPS (1977) Inititiation of shoots and callus from potato-tuber sprouts and axillary buds frozen at $-196^{\circ} \mathrm{C}$. Crop Improv $4: 48$ 53

Benson EE, Harding K, Smith H (1989) Variation in recovery of cryopreserved shoot-tips of Solanum tuberosum exposed to different pre- and post-freeze light regimes. Cryoletters 10:323-344

Chang Y, Barker RE, Reed BM (2000) Cold acclimation improves recovery of cryopreserved grass (Zoysia and Lolium sp.). Cryoletters 21:107-116

Chang Y, Reed BM (2000) Extended alternating-temperature cold acclimation and culture duration improve pear shoot cryopreservation. Cryobiology 40:311-322

Chen SA, Hajirezaei M, Peisker M, Tschiersch H, Sonnewald U, Bornke F (2005) Decreased sucrose-6-phosphate phosphatase level in transgenic tobacco inhibits photosynthesis, alters carbohydrate partitioning, and reduces growth. Planta 221:479-492

Fabre J, Dereuddre J (1990) Encapsulation-Dehydration: A new approach to cryopreservation of Solanum shoot-tips. Cryoletters $11: 423-426$

Golmirzaie AM, Panta A (2000) Advances in potato cryopreservation at CIP. In: Engelmann F, Takagi H (eds) Cryopreservation of tropical plant germplasm. Current research progress and application. JIRCAS, Tsukuba, pp 250-254

Hajirezaei M-R, Biemelt S, Peisker M, Lytovchenko A, Fernie AR, Sonnewald U (2006) The influence of cytosolic phosphorylating glyceraldehyde 3-phosphate dehydrogenase (GAPC) on potato tuber metabolism. J Exp Bot 57:2363-2377

Halmagyi A, Deliu C, Coste A (2005) Plant regrowth from potato shoot tips cryopreserved by a combined vitrification-droplet method. Cryoletters 26:313-322

Hannah MA, Heyer AG, Hincha DK (2005) A global survey of gene regulation during cold acclimation in Arabidopsis thaliana. PLoS Genet 1:e26

Hincha DK (1990) Differential effects of galactose containing saccharides on mechanical freeze-thaw damage to isolated thylakoid membranes. Cryoletters 11:437-444

Hirai D, Sakai A (1999) Cryopreservation of in vitro-grown meristems of potato (Solanum tuberosum L.) by encapsulationvitrification. Pot Res 42:153-160

Hirai D, Sakai A (2000) Cryopreservation of in vitro-grown meristems of potato (Solanum tuberosum L.) by encapsulationvitrification. In: Engelmann F, Takagi H (eds) Cryopreservation of tropical plant germplasm. Current research progress and application. JIRCAS, Tsukuba, pp 205-211
Hitmi A, Barthomeuf C, Sallanon H (1999) Cryopreservation of Chrysanthemum cinerariaefolium shoot tips. Effects of pretreatment conditions and retention of biosynthetic capacity. Cryoletters 20:113-120

Keller ERJ (2005) Improvement of cryopreservation results in garlic using low temperature preculture and high-quality in vitro plantlets. Cryoletters 26:357-366

Kryszczuk A, Keller J, Grübe M, Zimnoch-Guzowska E (2006) Cryopreservation of potato (Solanum tuberosum L.) shoot tips using vitrification and droplet method. Food Agric Environ 4:196-200

Leunufna S, Keller ERJ (2005) Cryopreservation of yams using vitrification modified by including droplet method: effects of cold acclimation and sucrose. Cryoletters 26:93-102

Levitt J (1972) Responses of plants to environmental stress. Academic Press, New York

Li PH, Fennel A (1985) Potato frost hardiness. In: Li HP (ed) Potato physiology. Academic Press, Orlando, pp 457-479

Li PH, Palta JP, Chen HH (1979) Freezing stress in potato. In: Lyons JM, Graham D, Raison JK (eds) Low temperature stress in crop plants. The role of the membrane. Academic Press, New York, pp 291-303

Li PH (1977) Frost killing temperatures of 60 tuber-bearing Solanum species. Am Pot J 54:542-456

Lohaus G, Buker M, Hussmann M, Soave C, Heldt HW (1998) Transport of amino acids with special emphasis on the synthesis and transport of asparagine in the Illinois low protein and Illinois high protein strains of maize. Planta 205:181-188

Marga F, Vebret L, Morvan H (1997) Agar fractions could protect apple shoots cultured in liquid media against hyperhydricity. Plant Cell. Tissue Organ Cult 49:1-5

Mastenbroek C (1956) Some experiences in breeding frost-tolerant potatoes. Euphytica 5:289-297

Murashige T, Skoog F (1962) A revised medium for rapid growth and bio assays with tobacco tissue cultures. Physiol Plant 15:473497

Niino T, Sakai A (1992) Cryopreservation of alginat-coated in vitrogrown shoot tips of apple, pear, and mulberry. Plant Sci 87:199206

Reed BM, Okut N, D’Achino J, Narver L, DeNoma J (2003) Cold storage and cryopreservation of hops (Humulus L.) shoot cultures through application of standard protocols. Cryoletters 24:389-396

Rolland F, Moore B, Sheen J (2002) Sugar sensing and signaling in plants. Plant Cell 14:185-205

Rolletschek H, Hajirezaei M-R, Wobus U, Weber H (2002) Antisense-inhibition of ADP-glucose pyrophosphorylase in Vicia narbonensis seeds increases soluble sugars and leads to higher water and nitrogen uptake. Planta 214:954-964

Schäfer-Menuhr A, Schumacher HM, Mix-Wagner G (1994) Langzeitlagerung alter Kartoffelsorten durch Kryokonservierung der Meristeme in flüssigem Stickstoff. Landbauforschung Völkenrode 44:301-313

Seibert M, Wetherbee PJ (1977) Increased survival and differentiation of frozen herbaceous plant organ cultures through cold treatment. Plant Physiol 59:1043-1046

Stewart GR, Larher F (1980) Accumulation of amino acids and related compounds in relation to environmental stress. In: Miflin BJ (ed) The biochemistry of plants. Academic Press, New York, pp 609-635

Stone JM, Palta JP, Bamberg JB, Weiss LS, Harbage JF (1993) Inheritance of freezing resistance in tuber-bearing Solanum species: Evidence for independent genetic control of nonacclimated freezing tolerance and cold acclimation capacity. Proc Natl Acad Sci USA 90:7869-7873 
Thieme R (1992) An in vitro potato cultivar collection: microtuberization and storage of microtubers. Plant Gen Res Newsl 88(89):17-19

Towill LE (1991) Cryopreservation. In: Dodds JH (ed) In vitro methods for plant genetic resources. Chapmann and Hall, London, pp 41-70

Urquhart AA, Joy KW (1982) Transport, metabolism, and redistribution of xylem-borne amino-acids in developing pea shoots. Plant Physiol 69:1226-1232 van Swaaij AC, Jacobsen E, Feenstra WJ (1985) Effect of cold hardening, wilting and exogenously applied proline on leaf proline content and frost tolerance of several genotypes of Solanum. Physiol Plant 64:230-236

Zhao MA, Xhu YZ, Dhital SP, Khu DM, Song YS, Wang MY, Lim HT (2005) An efficient cryopreservation procedure for potato (Solanum tuberosum L.) utilizing the new ice blocking agent, Supercool X1000. Plant Cell Rep 24:477-481 